\title{
La emigración y el exilio en la vida de Saturnino Tejera García, entre la Fraternidad y el Periodismo
}

\author{
Victoria María Sueiro Rodríguez \\ Doctora en Ciencias Históricas. Investigadora y Profesora Titular en la Cátedra de Historia de la \\ Universidad de Ciencias Médicas de Cienfuegos, Cuba. \\ Correo electrónico: vickysueiro@yahoo.es, filosofia4802@ucm.cfg.sld.cu
}

Fecha de recibido: 2 de marzo de 2015 - Fecha de aceptación: 27 de abril de 2015

\author{
Palabras clave \\ Emigración española, exilio republicano, masonería, Cienfuegos (Cuba), periodismo, Saturnino Tejera \\ García
}

\section{Keywords}

Spanish emigration, Republican exile, Freemasonry, Cienfuegos (Cuba), journalism, Saturnino Garcia Tejera

\begin{abstract}
Resumen
Saturnino Tejera García (Santa Cruz de Tenerife, 1900-Cienfuegos, 1956); emigró a Cuba alrededor de 1916 o 1917 y se estableció en Yaguajay, y, posteriormente, en Cienfuegos. Escritor, linotipista y periodista no profesional. Se inició en la Masonería en 1929 a la logia "Fernandina de Jagua"; en 1930 al Oddfelismo "Caballeros de la Luz". Regresó a Canarias a principios de la década del 1930; lo sorprendió la Guerra Civil Española y fue procesado por el Tribunal Supremo de la Masonería de Madrid por defender sus postulados; se exilió en Cienfuegos en 1945 y dedicó su ejecutoria a la Fraternidad y a la cultura; tuvo una sección periodística Fraternales, fundó la Hora Radial Fraternal y la logia "Federico Capdevila", donde resultó electo Primer Vigilante y representante ante la Gran Logia de Cuba; por lo que el objetivo del trabajo ha sido valorar sus marcados aportes a la Masonería y Periodismo locales.
\end{abstract}

\begin{abstract}
Saturnino Tejera García (Santa Cruz de Tenerife, 1900-Cienfuegos, 1956) migrated to Cuba around 19161917 and settled down in Yaguajay, and later in Cienfuegos. He was writer, typesetter and nonprofessional journalist. He started in Freemasonry in 1929 in the Lodge "Fernandina de Jagua"; in 1930 in the Oddfellows lodge "Caballeros de la Luz". He returned to the Canarian Island at the beginning of the 1930's. The Spanish Civil War surprised him, and the Supreme Court of Freemasonry in Madrid attacked him for defending his principles. Exiled to Cienfuegos in 1945, he dedicated his efforts to Fraternity and Culture. He had a section in a newspaper, Brotherhood, founded Brotherhood Radio Time, and established the Lodge "Federico Capdevila," where he was selected Prime Vigilant and representative in the Great Lodge of Cuba. Therefore, the objective of this paper is to assess his significant contributions to local Freemasonry and Journalism.
\end{abstract}

\section{Introducción}

El estudio de las migraciones ibéricas ha sido objeto de múltiples investigaciones, a la luz de la importancia que va adquiriendo la Historia Social. Estos 
estudios son de un extraordinario interés, si se tiene en cuenta la necesidad de rescatar la vida y obra de la gran cantidad de intelectuales, artistas, escritores, médicos, científicos, obreros, etc., que se han visto forzados a salir de sus respectivas regiones y buscar refugio en otras partes del mundo por disímiles causas. Tal fue el caso del escritor que nos ocupa, que por razones económicas primero, y políticas después, vivió casi toda su vida en Cuba, y específicamente en Cienfuegos, ciudad ubicada en el centro-sur de la Isla.

Esbozar el fenómeno migratorio en sus diversas facetas y vertientes, y dar vida a lo que ha quedado en la historia: los sufrimientos del inmigrante por lo dejado atrás, sus anhelos, sus vicisitudes, sus trabajo y sus días, sus reuniones, tradiciones, espacios de sociabilidad y costumbres, entre otros aspectos, son los elementos de primer orden para el estudio de las migraciones.

Este trabajo forma parte de un estudio mayor, que sobre la emigración española hacia Cienfuegos he venido realizando desde hace algún tiempo como miembro de la Asociación para el Estudio de los Exilios y Migraciones Ibéricos Contemporáneos (AEMIC), con sede en el Departamento de Historia Contemporánea de la Universidad de Educación a Distancia de Madrid, y como integrante de proyectos de investigación relacionados con la recuperación de la memoria histórica de los exiliados republicanos de 1939 en Cuba, que ha quedado dispersa fundamental, aunque no exclusivamente, en las publicaciones periódicas.

En la geografía de las ciudades se privilegió la vida de los emigrantes; y en ellas desplegaron una gama de actividades, que ha quedado registrada en la historia de cultura cubana, y en especial, en las páginas de la prensa periódica nacional, regional y local; y fue en las ciudades también donde pudieron integrarse a las asociaciones existentes o generar estructuras institucionales propias (clubes, asociaciones, órganos de opinión); tejieron redes sociales y de sociabilidad, crearon sus familias, establecieron relaciones profesionales, etc.; con el paso del tiempo fueron adentrándose e imbricándose en el país y apropiándose de una nueva identidad.

Estas razones nos han motivado a realizar el estudio de la personalidad y la obra del tinerfeño Saturnino Tejera García ${ }^{1}$.

\section{La emigracion. Los primeros momentos}

Saturnino Tejera García nació en La Laguna, Santa Cruz de Tenerife, el 22 de noviembre de $1900^{2}$. Hijo de Antonio y Buenaventura. En su natal Tenerife vivió los primeros años de su vida, fue monaguillo, pero la difícil situación por la que atravesaba su familia lo hizo emigrar en busca de trabajo y fortuna, cuando todavía era adolescente.

\footnotetext{
${ }^{1}$ Para mayor detalle véase el libro de Victoria María Sueiro Rodríguez, Perfil biobibliográfico del tinerfeño Saturnino Tejera García (Fuerteventura: Servicio de Publicaciones del Cabildo de Fuerteventura, 2007).

${ }^{2}$ Algunas fuentes indican la fecha de nacimiento el 1 ro de noviembre, se toma el 22 porque aparece con mayor frecuencia en los documentos consultados.
} 
Llegó a Cuba y se estableció inicialmente en el poblado de Yaguajay, al norte de la antigua provincia de Las Villas, pues algunos trabajos de crítica remitidos por él a Canarias están fechados en 1917 en aquel lugar sobre la Asociación Balompédica Canaria; ya en 1923 se encuentra en Cienfuegos vinculado a las labores agrícolas como obrero azucarero, trabajo que ejerció durante varios años.

\section{EI regreso a Canarias}

Todo parece indicar que hacia finales de 1926, quizás principios de 1927 Saturnino Tejera decidió regresar a Canarias; los motivos por los cuales decidió regresar lo desconocemos, pero suponemos que lo más probable haya sido el hecho de que estaba afectado por los problemas económicos que aquejaban a los inmigrantes de manera general ante la crisis por la que atravesaba el país.

El 23 de mayo de 1927 sale a la palestra pública en la Laguna de Tenerife el No. 1 del semanario literario Horizontes; tuvo como fundador a José A. Wangüemert y como director a Saturnino Tejera García. La revista de pequeño formato, contaba solamente de 8 páginas; núcleo de algunos de los integrantes de la llamada Generación del 27 canario. El semanario como publicación de corte literario dedicó espacio a poemas, cuentos, leyendas, crónicas de actualidad, crónicas literarias, así como también a publicar noticias breves de sociedad: fiestas literarias, exposiciones, concursos.

Participó en ese año en la Fiesta de los Nuevos Literatos en el Ateneo de la Laguna y en el Concurso de Coplas de esa institución de ese año Tejera resultó ser el premiado.

\section{América nuevamente}

En 1928 vemos aparecer su firma en el periódico La Correspondencia como periodista no profesional, era tipógrafo y atendía los linotipos; esto nos da la medida de que se encuentra nuevamente en Cienfuegos dedicado a las labores periodísticas. De estos años datan algunos trabajos suyos de crítica literaria, poemas, notas breves y narraciones cortas.

Junto a la huella histórica de tanta letra que pasó por su máquina, puede encontrarse también la marca propia de su existir; los versos del poeta. Su deseo de hacer literatura lo llevó a ocupar el cargo de responsable de la página "De la vida literaria", sección semanal dominical que comenzó a ver la luz a partir del 8 de julio de 1928; también tuvo en su haber las secciones fijas tituladas "Comentarios" y "Facetas".

En el 1929, hizo la disertación en el Roof Garden del Hotel San Carlos para hacer su entrada al Ateneo de Cienfuegos, con el trabajo titulado La Poesía. En ese mismo año tuvo una sección fija en La Correspondencia denominada "Pequeños Comentarios", que firmaba con el seudónimo de TINERFE, donde diariamente publicaba una crónica, entre las que merecen ser citadas: Páginas doctrinales, A lo que da derecho la amistad, Del momento político, La cultura y la vida. 
Por estos años ya había conformado su familia cubana. Contrajo matrimonio con Zoila Montejo Robledo del cual tuvo dos hijos: Nivaria ${ }^{3}$ y Tinerfe.

Perteneció al Liceo Canario y figuró entre sus directivos y al Nuevo Centro Canario de Las Villas, fundado en el 30.

En junio de 1930 se produjo la segunda visita de Federico García Lorca a esta ciudad $^{4}$, y Tejera publicó una crónica titulada La Tangibilidad de los Ídolos, en la cual realiza una crítica desfavorable al poeta gitano.

Con motivo de la visita en noviembre de 1930, del cónsul de España, el Licenciado Francisco Campos Aravaca, Tejera fue uno de los más entusiastas organizadores del homenaje por parte del Liceo Canario y de la Hispanocubana en esta ciudad de la que era miembro y activo colaborador. Las palabras centrales del acto corrieron a su cargo, donde expresó:

Yo quiero explicar, - único objeto de estas cuartillas-, el por qué de este testimonio de gratitud y afecto, que tan cariñosa acogida ha tenido, no solamente entre las más destacadas figuras de la colonia española, sino también de la sociedad cienfueguera (...).En esta obra de comprensión y de compenetración, con sana levadura hispana, siempre habéis puesto vuestros mejores deseos y entusiasmos seguros de que, conocernos es ya comenzar a amarnos; y compenetrándonos nosotros por nuestra parte con los hombres representativos de nuestra nación - representativos, no solo por el título, sino por su mentalidad y por sus hechos-, es buscar un acomodo digno en la entraña misma de la patria española ${ }^{5}$.

\section{Entrada a la fraternidad}

Los inicios de Saturnino en el mundo de la Fraternidad hay que buscarlos en la Logia AJEF (Asociación de Jóvenes Esperanza de la Fraternidad). Allí se inició a mediados de los años veinte. Esta asociación era algo así como el primer paso antes de pasar a ser miembro de una logia donde se estudiaban algunos postulados teóricos de la fraternidad. Perteneció a los rosacruces y a los bahai”s; pero su entrada a la Masonería ocurrió el 11 de diciembre de 1929, a la Logia Fernandina de Jagua, y ya el 8 de mayo de 1930 había recibido el Segundo Grado; el 24 de marzo de 1930 se inició en la Orden Oddfelows "Caballeros de la Luz". A partir de entonces, consagró su vida a la masonería local y "donde más alto enarboló su penacho".

\footnotetext{
${ }^{3}$ Nivaria nació en Cienfuegos, el 30 de septiembre de 1929. Muy pequeña fue llevada por sus padres a Tenerife donde vivió toda su infancia. Escritora. Actualmente reside en París.

${ }^{4}$ La primera visita fue en el mes de abril de ese mismo año.

${ }^{5}$ La Correspondencia, 25 de noviembre de 1930: 5.

${ }^{6}$ Lincoln George. Saturnino Tejera García. Datos extraídos de los archivos de las logias de Cienfuegos.
} 


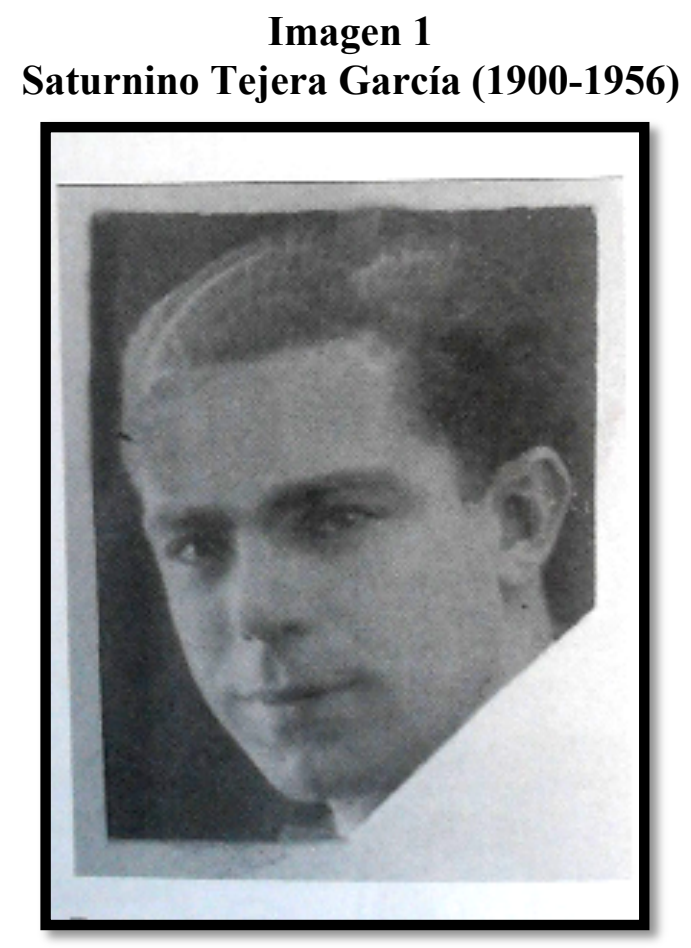

Foto de Saturnino Tejera a finales de la década del 20 que acompaña su expediente de masón en la logia Fernandina de Jagua. Cortesía de un hermano masón.

Conoció y amó profundamente la vida y obra martianas y el 19 de mayo de 1930 dictó una conferencia sobre José Martí en Fernandina de Jagua, lo hizo como cálido tributo de admiración y respeto a la memoria del Apóstol. ${ }^{7}$.

La nostalgia que sentía por su terruño unido a la crítica situación que presentaba Cuba en esos años, y los avatares de la vida devolvieron a Tejera a sus playas en 1933, donde continuó su labor periodística y fraternal.

\section{Regreso a Canarias. La Guerra Civil Española}

El regreso de Tejera a Canarias se produjo aproximadamente en 1933. Como a tantos otros emigrados españoles "La realidad encontrada en Cuba chocaba con los sueños de todos los jóvenes que veían en América la tierra de jauja, donde el trabajo sería mucho más liviano que el dejado atrás y donde pronto la fortuna les sonreiría"». La situación cada día se hacía más crítica en Cuba y se agudizaba la crisis económica y política.

Llegó a Tenerife con su familia y se reintegró a las labores del periodismo vinculado a Hoy (Diario Republicano de Tenerife), La Prensa, La Tarde, donde publicaba noticias del acontecer cubano.

\footnotetext{
${ }^{7}$ Véase La Correspondencia 20 de mayo de 1930: 12.

${ }^{8}$ Consuelo Naranjo Orovio. "Memoria de los trabajos y los días. Historias de la emigración a Cuba", Anuario TEBETO IX (1995), 92-93.
} 
Se vinculó a los círculos artísticos y literarios de Tenerife, conoció a la intelectualidad tinerfeña del momento, intimó con Luis Álvarez Cruz y con el poeta Pedro García Cabrera, militante de izquierda del Partido Socialista Obrero Español (PSOE).

Los tiempos difíciles por los que atravesaba su terruño producto de la crisis económica mundial, obligaron a Saturnino a viajar a la parte continental de España en busca de mejores horizontes de trabajo; y cuando ya había obtenido alguna mejoría en sus propósitos se produjo la sublevación franquista de 1936 en contra de la República. Las referencias encontradas refieren su estancia en Madrid.

Militó en el PSOE y fue dirigente político. En Madrid lo sorprendió la guerra y por republicano y su militancia de izquierda sufrió cárcel y campos de concentración. Fue también procesado en el Tribunal Especial de Represión de la Masonería por defender los ideales y postulados de la misma.

La realidad vivida por Nivaria, su hija pequeña que sufrió y sintió de cerca la guerra y los difíciles días por los que atravesó su padre encarcelado, encontraron luego reflejo artístico en las páginas de su novela El Barranco, dedicada en la primera edición cubana a su padre "Hasta mi padre en su muerte, en nombre suyo a todos los españoles, raza de humillados",.

En 1945 Tejera decidió abandonar para siempre su terruño como exiliado político. A partir de su llegada su patria sería Cienfuegos, la ciudad cubana que le acogió en su seno como emigrado, la ciudad de su familia, y a ella se entregó en cuerpo y alma para toda su vida.

\section{El exilio en Cienfuegos}

En marzo de 1945 ya Saturnino se encuentra nuevamente en Cienfuegos, y el 10 de abril de ese año, se anunciaba la llegada de los esposos Tejera-Montejo, cuya residencia fijarían en la calle de Argüelles \#121. En esta ocasión llegaba no en busca de fortuna, sino buscaba refugio para dar paz a su vida que durante años sufrió los vejámenes de las prisiones y los campos de concentración. Esta vez el diario El Comercio le abrió sus puertas y Tejera volvía a su noble oficio de fundir ideas en barritas de plomo, y le quedó tiempo para hacer periodismo y poesía.

Su ocupación fundamental era mecánica de Linotipo, y le llamaban "el médico de las locas" $" 10$ en alusión a una película de igual nombre, y la locas eran precisamente los linotipos. Su vida fue la imprenta. Además de su trabajo en El Comercio tenía una contrata en el diario local La Correspondencia.

\footnotetext{
${ }^{9}$ Nivaria Tejera Montejo, El Barranco (Santa Clara: Universidad Central de Las Villas, Departamento de Relaciones Culturales, /Impresiones Ucar, García, S.A/, 1959).

${ }^{10}$ Lincoln George. Entrevista concedida el 24 de octubre del 2000 a la edad de 82 años.
} 


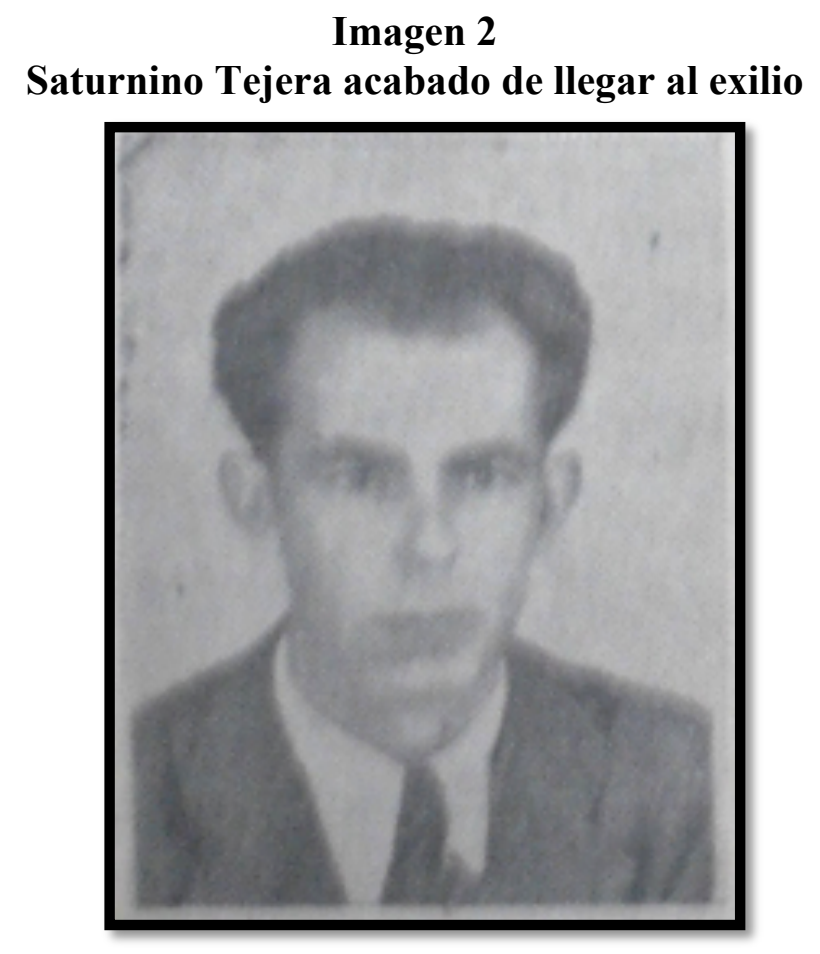

Fuente: El Comercio, 20 de marzo de 1945, p. 1

$\mathrm{Su}$ obra literaria y periodística es extensa y variada. Dentro de su obra en prosa de estos años destacan las que resaltan sus ideales republicanos: "En recuerdo de Manuel Azaña", " ¡Catorce de abril! 1931", "14 de abril de España", "Un hombre de suerte (dedicada a Franco), "14 de abril"; las que ponen de manifiesto la entrañable nostalgia por su patria y sus Islas Canarias, y las que abordan la figura de José Martí, entre ellas: "Martí en Canarias" y "La voz de la sangre en Marti"; así como también crónicas artísticas, históricas y literarias entre las que deben citarse: "Amanecer y ocaso", "La responsabilidad histórica", "La obra artística de Hilda Bembibre", "Carlos Era: El caballero del arte", "Misión histórica y poética del Ateneo", "Caracol: eslabón entre dos épocas", "Signo: Revista de Arte"; y otras, donde refiere el tema de la guerra: "Justicia de guerra", "El archivo nazi”, "El pájaro herido”, "El dolor de Europa”, etc ${ }^{11}$.

En esta etapa se reintegró a las actividades del Ateneo al cual había pertenecido durante su etapa de emigrado, y al Círculo de Amigos de la Cultura; también frecuentó las distintas organizaciones fraternales en las que ofrecía discursos y conferencias. En el Oasis Teosófico Martiano disertó en varias oportunidades sobre José Martí y en las fechas de celebración del Día del Idioma, como el del año 1955, donde Saturnino dio lectura a unas emotivas cuartillas, haciendo un somero recorrido por la historia española

\footnotetext{
${ }^{11}$ Véase Anexo titulado "Aproximación a la bibliografía cubana de y sobre Saturnino Tejera García" aparecido en el libro de la autora de este trabajo Perfil biobibliográfico del tinerfeño Saturnino Tejera García (Fuerteventura: Servicio de Publicaciones del Cabildo de Fuerteventura, 2007): 155-191. En él se recoge la bibliografía activa (crónicas, artículos, poemas, cuentos, epistolario durante la emigración y el exilio; lo publicado en la sección FRATERNALES) y la bibliografía pasiva.
} 
de fines del siglo XIX, enfocando seguidamente la labor inmensa de dos genios de la literatura española: Lope de Vega y Cervantes ${ }^{12}$.

\section{Saturnino Tejera en la fraternidad cubana}

En su etapa de exiliado luchó incansablemente por la masonería local, a la que dio todo su aliento y esfuerzo y donde su ejecutoria fue más intensa hasta su muerte.

Como ha señalado Manuel Zabala "Cada logia masónica, debe estimarse como un centro de cultura, de civismo y de progreso fecundante" ${ }^{13}$ y es precisamente en estos recintos masónicos "donde se aconseja la constancia por la instrucción de los hombres"14.

No solo en Cienfuegos, sino en las diferentes logias de la jurisdicción, y otros lugares de Cuba Saturnino dejó su vasta cultura, y donde desarrolló actividades a favor del bienestar de Cienfuegos y sus hermanos de la Fraternidad.

En el diario El Comercio se le designó como redactor de la sección FRATERNALES que dio comienzo el 3 de agosto de 1948, a través de la cual diariamente reflejaba el acontecer de la fraternidad en esta ciudad, reseñaba actos masónicos, lo acontecido en las tenidas blancas, biografías de maestros de la Fraternidad Universal y Local, conferencias sobre escritores y literatos masones como Rubén Darío, el padre del Modernismo latinoamericano. Todos sus trabajos en esta etapa aparecen firmados bajo el seudónimo de SATURNO, pero a partir del 10 de junio de 1950 apareció su nombre completo en el logotipo de la sección.

En su primera salida comentaba Tejera: "Y es hora que nos apartemos un poco de la rutina histórica de trabajar solamente en los talleres. Ya es hora de salir a la calle, de trabajar en la calle bajo la luz del sol real (...)" ${ }^{\prime 15}$.

Es destacable la crónica del 19 de agosto de 1948, en la cual Saturnino dedicó la sección FRATERNALES a la intelectual y feminista canaria Mercedes Pinto, que permaneció en Cuba durante 1935 y 1936, los años de la Guerra Civil española y luego hasta 1943 en el exilio, se trasladó a México donde se exilió definitivamente hasta su fallecimiento, ocurrido en 1976. En su trabajo Tejera refiere aspectos relacionados con el pensamiento de esta mujer que luchó incansablemente por el derecho de las mujeres desde las tribunas de las logias masónicas, donde ofreció discursos y conferencias y en otros espacios defendió sus ideales feministas y republicanos.

Destacable también son sus artículos de la sección FRATERNALES dedicados a Antonio Maceo masón, el invencible y mito guerrero de las huestes libertadoras cubanas, al que le dedicó el 6 de diciembre de 1948 un trabajo sobre su personalidad histórica y una semblanza biográfica, y el día 8 del mismo mes, dio a conocer la

\footnotetext{
${ }^{12}$ El Comercio "Se conmemoró solemnemente el Día del Idioma en el Oasis Teosófico Martiano", 3 de mayo de 1955: 1-2. En aquella ocasión el acto fue pospuesto para el día 1ro de mayo.

${ }^{13}$ Manuel Zabala Pérez, Instituciones nacionales (La Habana: Carasa y Cía, 1930): 192

${ }^{14}$ Zabala, Instituciones, 195.

${ }^{15}$ Saturno (Seud.), "Fraternales", El Comercio, 3 de agosto de 1948: 3
} 
concentración masónica llevada a cabo por masones de diferentes logias de la República ante el Cacahuált, lugar donde descansan los restos del insigne patriota.

\section{Imagen 3 \\ Logotipo inicial de la sección FRATERNALES a cargo de Saturnino Tejera en el periódico El Comercio. En la foto aparece Antonio Maceo, el Titán de Bronce}

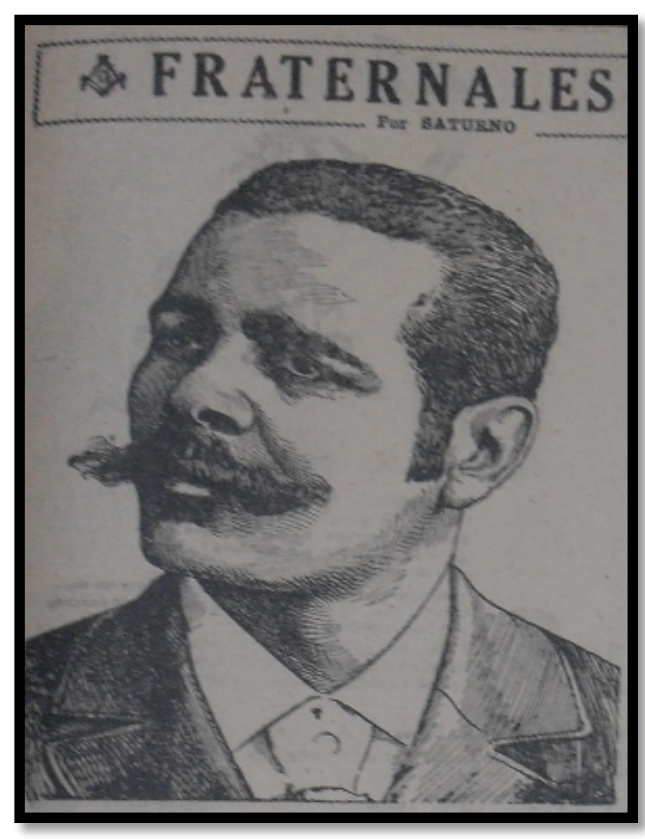

Fuente: El Comercio, 6 de diciembre de 1948, 3.

Su quehacer divulgativo se extendió a la vida y obra de José Martí masón, que al igual que Maceo proclamaba desde las tribunas de las logias sus ideales independentistas.

Con la devoción y la entrega que le caracterizaba, asistía puntualmente a los actos masónicos que se celebraban en diversas logias de la ciudad; en ocasión de la inauguración de la Casa-templo de Perla del Sur número 61, asistió en representación del periódico El Comercio y en el acto hizo uso de la palabra saludando el advenimiento de la nueva institución fraternal.

En ocasión de otorgársele el grado de Maestro Masón y otros tres hermanos más, la sección FRATERNALES reseñaba las cuartillas leídas por el hermano Ricardo Peña de Armas en la cual destacaba las dotes y cualidades de Tejera, decía Peña:

De este grupo se destaca, por sus conocimientos teosóficos, el culto compañero, hombre modesto, pero cultísimo, que sabe ya de los sufrimientos de las persecuciones a la Masonería en tierras del dictador español (...) Como hombre de principios y masón(...) este noble hermano logró escapar con vida de aquel infierno de persecuciones y llegar hasta nuestras playas, donde él sabe que se le estima y quiere. Aquí enseguida comenzó su labor de reconstrucción espiritual y material, en esta propia ciudad (...) Hombre de elevados principios morales y profundamente fraternal el querido hermano Tejera se vinculó estrechamente a 
todos los círculos de superación espiritual, y su labor se ha distinguido, y nos ha servido y sirve para encaminar e inspirar nuestros pasos por los senderos de la coordinación de nuestros valores fraternales (...) En el periodismo local (...) mantiene una sección diaria con el título de Fraternales que es un himno vivo a nuestras preocupaciones y un nexo de unidad más perfecta y sincera de todas las fraternidades ${ }^{16}$.

El 15 de septiembre de 1948 se celebraron las elecciones en la logia Fernandina de Jagua, resultando electo Orador Adjunto de la citada institución.

También divulgó los postulados de la masonería a través la HORA FRATERNAL $D O M I N I C A L$, que eficazmente inauguró y llevó a cabo a partir del 2 de enero de 1949, fecha en que salió al aire el primer programa radial a través de la emisora local.

En varias oportunidades a Saturnino se le ratificó como Orador Adjunto, cargo que desempeñó eficazmente., y por este nombramiento participaba constantemente en actos de toma de posesión de diferentes logias de hombres y mujeres; en una ocasión expresó en la Asociación Fraternal Hijas de Acacia No. 32 lo siguiente:

Quisiéramos ver armonizados los sentimientos fraternales del hombre y de la mujer, porque pensamos siempre que cuando el alma pone visión de amor en las cosas, empezamos por encontrar en las dispares recíprocas resonancias, como si unas cosas fecundaran a las otras, como si cada una reflejara a las restantes ${ }^{17}$.

A partir del 10 de junio de 1950, en la sección FRATERNALES comenzó a aparecer su nombre completo, y además aparecieron símbolos de la Fraternidad.

\section{Imagen 4}

Logotipo de la sección FRATERNALES

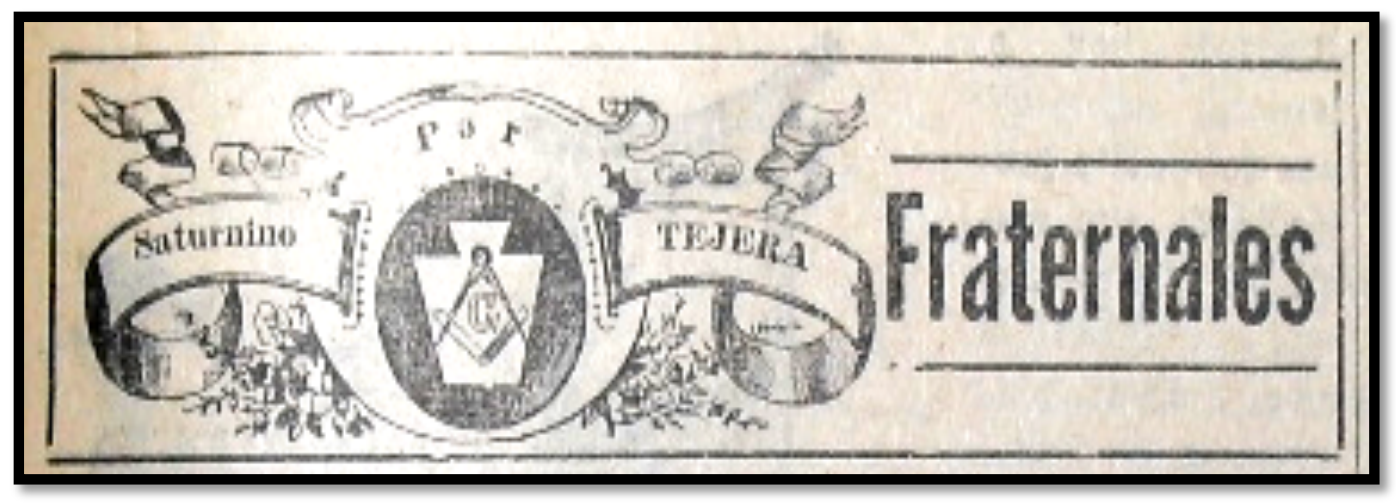

Fuente: El Comercio, 10 de junio de 1950, 3.

\footnotetext{
${ }^{16}$ Saturno (Seud.), "Fraternales", El Comercio, 29 de octubre de 1948: 3.

${ }^{17}$ Saturno (Seud.), "Fraternales", El Comercio, 22 de marzo de 1950: 3.
} 
Recibió constantes homenajes y condecoraciones de las logias de Cienfuegos, Palmira, Cumanayagua y en otros valles de la jurisdicción, por su elocuente discurso y su labor fraternal.

Su participación fue constante en el desarrollo cultural dentro de los recintos masónicos, al cual vinculó a su hija Nivaria, fundamentalmente, en las tenidas blancas donde participaba con recitales de poesías, comentarios de libros. En la sesión mensual de la Cámara de Maestros de Fernandina de Jagua celebrada el 27 de abril de 1949, se acordó enviar a Nivaria una calurosa felicitación por su triunfo literario y haber sido premiada con una Flor Natural una de sus composiciones poéticas en celebración del 130 aniversario de la fundación de Cienfuegos.

La conmemoración del 71 aniversario de la fundación de la logia Fernandina de Jagua se festejó con disímiles actos culturales y fraternales; en esa oportunidad se le entregó a Nivaria y a su padre diplomas de reconocimiento por la labor cultural desplegada; después de la entrega del diploma con expresión de gratitud Nivaria recitó unos versos y a Saturnino se le obsequió otro diploma por su labor radial y fraternal desde las páginas del diario El Comercio y la emisora CMHJ.

El vínculo de Saturnino con el Oasis Teosófico Martiano era constante; así podemos mencionar su participación en el acto por la celebración del 98 aniversario del natalicio del Apóstol, en el cual brindó su aportación literaria con una conferencia donde relató "detalles desconocidos en relación con Doña Leonor Pérez Cabrera, la madre de Martí, dando lectura seguidamente a un bello trabajo del maestro poco divulgado, y que figura como prólogo a una obra de Ceniceros"18.

Aunque nunca se inició en otra importante logia cienfueguera "Asilo de la Virtud", se vinculó a ella a través del Club Masónico del taller de la citada logia, y en las elecciones celebradas en enero de 1951 resultó electo Director de Recreo y Cultura.

Después de dos meses de ausencia por su enfermedad, reapareció la sección FRATERNALES el 3 de mayo de 1951, ya comenzaban a vislumbrarse los primeros síntomas de la enfermedad que lo llevaría a la muerte. En ella expresó sus agradecimientos al Cuerpo Facultativo Médico del Sanatorio de la Colonia Española de Cienfuegos y a las instituciones fraternales, por el apoyo brindado durante su etapa postoperatoria. Entre los años 1951 y 1953 la publicación de esta sección se vio interrumpida debido a su enfermedad que se agudizaba y durante todo el año 1952 no apareció ninguna.

Pero su mayor ejecutoria y desvelo fue fundar, el 2 de enero de 1953, la tercera logia masónica de Cienfuegos "Federico Capdevila", junto a otros hermanos masones; desempeñó el cargo en varias directivas de Primer Vigilante; fue además, Diputado y el representante por esta logia ante la Gran Logia de Cuba en La Habana.

\footnotetext{
18 "Se conmemora el natalicio del Apóstol en el Oasis Teosófico Martiano", El Comercio, 22 de marzo de $1950,3$.
} 


\section{Imagen 5 \\ Noticia aparecida en el diario local El Comercio sobre la visita del Gran Maestro de la Logia de Cuba a Cienfuegos}

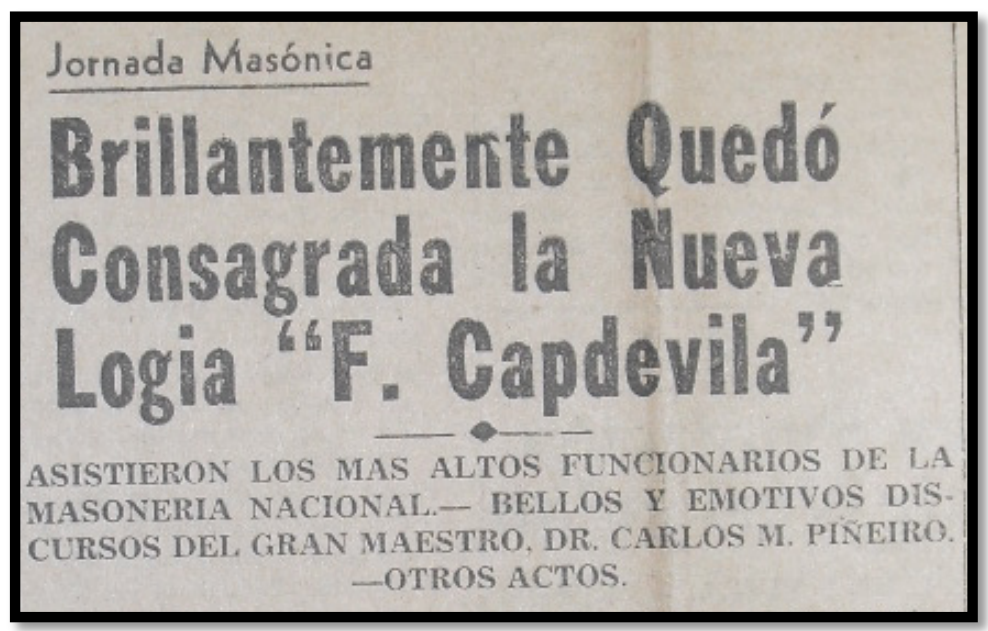

Fuente: El Comercio, 25 de mayo de 1953, 1.

Años más tarde, los masones de esta logia decidieron ubicar un cuadro de madera a relieve que le hicieron a Saturnino y aún permanece en esa logia masónica; por su labor de acercamiento fraternal recibió reiterados homenajes en la logia "Francisco Sánchez Curbelo" de Cumanayagua.

A finales de 1953 es recluido nuevamente en el Sanatorio hasta marzo de ese año donde se le sometió nuevamente a una intervención quirúrgica. Aun enfermo siempre tuvo ánimo para visitar y estrechar lazos fraternales con miembros de otras logias de la localidad y de la región.

Como fervoroso martiano que fue, siempre buscaba lugar para ofrecer sus charlas y discursos sobre el Maestro. El 12 de enero de 1954 pronunció una amena disertación en el Oasis Teosófico Martiano con el título "La voz de la sangre en Martí". Participó también en los actos celebrados en ocasión de las visitas reiteradas del también exiliado Manuel Isidro Méndez a esta institución; de igual manera colaboró en la Revista Teosófica Cubana.

Durante mucho tiempo se mantuvo alejado del Oddfelismo y pidió su reingreso en 1955 en Jagua No 21 de la I.O.O.F; en las palabras que pronunció por tal motivo expresó:

(...) Los oddfelows no podemos ser nunca simples espectadores, como en el teatro de ficción. Por eso he querido entrar en la vida activa del oddfelismo, para ser actor de mayor o menor categoría, pero intérprete al fin, de la magna obra, de nuestra obra, de la obra de todos ${ }^{19}$.

Entregado con tesón a la Fraternidad cienfueguera, ya corría el año 1956 y poco podía hacer, padecía de cáncer de pulmón y permaneció recluido durante meses en el

${ }^{19}$ Saturno (Seud.), "Fraternales", El Comercio, 18 de julio de 1955, 8. 
Sanatorio de la Colonia Española. Días antes de morir corrigió las pruebas de plana de su único libro de versos "Vesperal" que salió a la luz postmortem, en marzo de 1957.

\section{Su muerte}

El día 17 de noviembre de 1956 a las 4 de la tarde, llegaba el fin de su vida tras larga y penosa enfermedad; su muerte se certificó por colapso funcional del corazón; estaba recluido en el Sanatorio de la Colonia Española. Sus restos fueron sepultados en la sección Y- 16, del Lote No 98, del Panteón de la Logia Jagua No 21, y el 17 de noviembre de 1959 fueron exhumados y aún permanecen guardados en el mismo panteón de la citada logia, en la misma sección, Lote 21.

Su muerte conmovió a la sociedad cienfueguera y los periódicos publicaron sentidas crónicas por su fallecimiento. Una crónica expresaba:

Había salido expatriado de su lejana tierra, y tenía ese pálido reflejo del hogar allende los mares. Quiso con sinceridad rayana en lo idealista, a la tierra cubana que le acogió en su seno. Quizás Cienfuegos tenga con él la deuda de un amor constante y efusivo, tanto a la ciudad que revivió de un poco de felicidad sus postreros años, como por lo mucho que él quiso a la Perla del Sur ${ }^{20}$.

Los poetas locales se inspiraron ante la muerte de tan apreciado colega; Segundo Serrano Fernández le dedicó un poema que tituló “In memoriam (A Saturnino Tejera García), y Luis F. Gallardo el titulado "A Saturnino Tejera” que reproducimos a continuación:

\section{"A Saturnino Tejera" \\ Si muero, dejad el balcón abierto \\ García Lorca}

A él también manos amigas,/ dejadle el balcón abierto, para que sus ojos fijos/ sigan podando su pecho.

Sus jardines de ternura/ que le aromaban el aliento, y le prendía en los labios/ una azucena riendo.

Para que puedan sus manos/ acariciar su desvelo. para que sueñe dormido/ lo que ya soñó despierto, desenhebrando distancias/ con agujas de silencio.

A él también manos amigas, /dejadle el balcón abierto.

\section{Vesperal: su último adiós}

Presidida por Florentino Morales Hernández, la Sección de Literatura del Ateneo de Cienfuegos se encargó de publicar su libro de versos Vesperal, quien expresó en las palabras que le escribiera en el reverso de la portada:

\footnotetext{
${ }^{20}$ Juan Ferrán, "El deceso de Saturnino Tejera”, El Comercio, 23 de noviembre de 1956, 6.
} 
(...) su espíritu vivió siempre enamorado de la poesía, en la que no llegaron a cuajar plenamente, por urgencias materiales inmediatas, los sueños y visiones que siempre lo acompañaron, lo mismo en las horas de alegría que en las de dolor. Muchas veces nos dijo que su máxima aspiración era alcanzar a través de su hija Nivaria, que era como una prolongación de su vida, la plenitud a que había aspirado inútilmente. La selección y revisión de los poemas contenidos en este libro, que terminó precisamente la víspera de su muerte (...) endulzó seguramente el dolor de sus últimos días en la tierra. Muchas veces contemplamos cómo la lectura de una imagen o un giro que le complacía borraba con una leve sonrisa el amargo rictus que la cruel enfermedad había tallado en sus labios...Tejera será siempre recordado con cariño de hermano por quienes tuvimos el privilegio de acercarnos al tierno reducto de su intimidad, asistiendo al maravilloso espectáculo de un puro corazón de poeta sempiterno y de un cerebro siempre en tensión, como un arco, hacia todos los vientos del espíritu ${ }^{21}$.

Vesperal fue su último adiós. En el título del libro está implícito el contenido del mismo. Libro de canto llano que contiene el de vísperas ${ }^{22}$, y ya Saturnino estaba en la víspera de su muerte, de ahí el título que lleva su libro. La dedicatoria es todo un poema en sí: "Con perdón de Nivaria, mi hija, me doy esta escapada por la puerta lírica antes que se ponga el sol, para dejarle siquiera unas raíces verdes del árbol que quiso ser y no fue".

Por más que Saturnino nació y vivió en dos islas rodeadas de mar, y haya tenido que cruzar el mar hacia la emigración y el exilio, no encontramos, sin embargo, referencias marcadas en su libro del motivo marinero. De los once poemas que lo integran solo hace alusión al mar o a la flora y fauna marinas en cuatro de ellos: Abismales, Volutas del humo, Barquitos de papel, y sOl. En el libro no aparece el mar como identidad de todos o de la gran mayoría de los escritores y poetas canarios ${ }^{23}$.

Cierra el libro el poema Sol, en él el ambiente está desolado: la arena es caliente, el mar está seco, el viento petrificó las espumas y él le implora

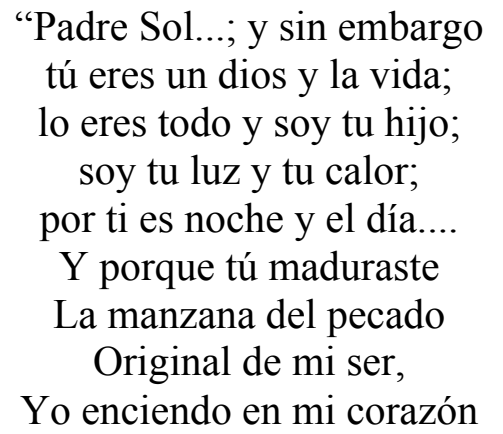

\footnotetext{
${ }^{21}$ Florentino Morales, "Nota-Prólogo al libro Vesperal, de Saturnino Tejera. 2" (Cienfuegos: Ateneo de Cienfuegos, 1957).

${ }^{22}$ Según se define en el Diccionario Manual de la Lengua Española, la víspera es el día que antecede inmediatamente a otro determinado.

${ }^{23}$ Véase al respecto el artículo publicado por Luis León Barreto, "El mar en la poesía de Tomás Morales y Pedro García Cabrera", Revista de Filología 6-7 (1987/1988): 227-238.
} 
La luz de mi pensamiento,

Para alumbrarme las sombras

En las horas de tu ausencia....

Era ya el ocaso de una vida que se apagaba para siempre, se ocultó el sol radiante para el tinerfeño Saturnino Tejera García.

\section{Conclusiones}

Mucho habría que investigar sobre la vida y obra de este hombre canario que se asentó en la Perla del Sur; dejamos al menos una muestra en estas páginas de lo mucho que aportó a la Fraternidad desde su quehacer como masón y periodista.

La Masonería y el Oddfelismo, así como la cultura cienfuegueras tuvo en Saturnino Tejera García a uno de sus más altos exponentes durante los años que vivió como emigrado y exiliado en esta ciudad; luchó incansablemente en pro del adelanto sociocultural de Cienfuegos y estuvo en cuantos comités a favor de ella pudieron existir; a la Perla del Sur entregó los mejores años de su vida, que ha quedado reflejada y olvidada en el linotipo ardiente del recuerdo.

\section{Fuentes}

Expediente de iniciación de Saturnino Tejera García en la logia Fernandina de Jagua.

El Comercio (Cienfuegos), años 1944-1959.

George, Lincoln. "Entrevista personal concedida el 24 de octubre del 2000 a la edad de 82 años". Cienfuegos, Cuba.

George, Lincoln. "Saturnino Tejera". Datos extraídos de los archivos de las logias cienfuegueras.

La Correspondencia (Cienfuegos), años 1928-1931, 1945-1961.

Revista Horizontes (La Laguna), 4 números, 1927.

\section{Bibliografía}

Bouclé Valdés, Luis. Meritísima y centenaria logia Fernandina de Jagua: Una centuria después 1878-1978. Cienfuegos: s.n, s.a.

León Barreto, Luis. "El mar en la poesía de Tomás Morales y Pedro García Cabrera". Revista de Filología 6- 7 (1987/1988): 227-238.

Morales, Florentino. "Nota-Prólogo al libro Vesperal, de Saturnino Tejera. 2". Cienfuegos: Ateneo de Cienfuegos, 1957.

Naranjo Orovio, Consuelo. "Memoria de los trabajos y los días. Historias de la emigración a Cuba". Anuario TEBETO IX (1995): 92-93.

Rumbaut Yanes, Vicente. La Masonería y el Odffelismo en Cienfuegos: Páginas históricas 1878-1938. Cienfuegos, 1938. 
Sueiro Rodríguez, Victoria María. Perfil bibliográfico del tinerfeño Saturnino Tejera García. Fuerteventura: Servicio de Publicaciones del Cabildo de Fuerteventura, 2007.

Tejera Montejo, Nivaria. El Barranco. Santa Clara: Universidad Central de Las Villas, Departamento de Relaciones Culturales, Impresiones Ucar, García, S.A, 1959.

Zabala Pérez, Manuel. Instituciones nacionales. La Habana: Carasa y Cía, 1930.

\section{Anexo}

Carta remitida por el hermano Rafael Martínez Pichs a Saturnino Tejera con motivo de la irregularidad de la salida de la sección FRATERNALES.

Cienfuegos, 6 de junio de 1949

HERMANO Saturno: Soy asiduo lector de tus FRATERNALES del periódico EL COMERCIO y créeme que veo con verdadero disgusto que las misma no aparezcan todos los días, como fuera mis deseos y el de todos los masones, pero no sé si es por falta de material diario para poderla publicar; pero bueno, ya sea por una cosa o la otra, todas las logias de la jurisdicción, a las que distintas veces has hecho llamamientos para que colaboren contigo, deben ayudarte a que esas FRATERNALES vean la luz diariamente, ya que tienen que representar para la Fraternidad el faro y guía de nuestros trabajos o de nuestro desenvolvimiento de la misma.

Estoy en la seguridad mi q.h., que todos los venerables maestros tienen que reconocer lo beneficiosa de tu labor, y, por lo tanto, deben exigir, si cabe, a los hermanos secretarios, que te comuniquen todos los actos o motivos que pudieran ver en tu sección, para que la misma cuente diariamente con el material necesario para que nunca falten ni dejen de publicarse éstos.

Todas las logias e instituciones fraternales, de las tantas que hay en nuestra jurisdicción, deben colaborar contigo a que las FRATERNALES que tú escribes, no carezcan nunca del material necesario para que cada día sean más grandes y tengan dentro de la dirección del periódico el respeto que han tenido hasta ahora.

No quiero molestar más tu atención, pero sí debes saber que puedes mandar en lo que gustes a tu affmo. Hermano.

(Fdo) Rafael Martínez Pichs

Logia Fernandina de Jagua

Fuente: El Comercio, "Fraternales", 8 de junio de 1949, 3. 